\title{
AMERICAN AND INDONESIAN SITCOMS: A TRANSNATIONAL ANALYSIS ON "FRIENDS" AND INDONESIAN SITCOMS
}

\author{
Teguh Puja Pramadya \\ teguhpuja@gmail.com
}

\begin{abstract}
The fact that Indonesia adopts many programs from American popular culture, especially the situation comedy format, makes reruns and reduplications at the national level, and makes them into primetime programs on most of the private television at stations demonstrates the strength of American cultural influence in Indonesia. Although, there are differences and adjustments in some parts of the program, modifying to the culture and customs of the people of Indonesia. The question arises, whether the entertainment producers in Indonesia nowadays were deliberately imitating and duplicating some imported variety and comedy format for the sake of popularity in public television in Indonesia or whether the traditional format of comedy in Indonesia is now being replaced with variety and comedy formats imported from America.

This study is carried out in the framework of American Studies. To carry out the analysis, the writer made use of the grounded research and comparative study approach and Stuart Hall's theory of representation, to see the scope for negotiation and opposition on the part of the audience as an active part of the media consumption and how audience members make meanings and understand reality through their use of cultural symbols in both print and visual media. The object of the study is limited to the representation in Friends, as an example of an American sitcom, and to the representation in four Indonesian sitcoms, namely Keluarga Masa Kini, Tetangga Masa Gitu, Saya Terima Nikahnya and The East.

The findings of selected episodes in Friends and Indonesian sitcoms, indicate some similarities and differences towards the trends that sitcoms have used. It is likely that American and Indonesian sitcoms use almost the same conventions of sitcom narrative, but, they also show some differences towards the content of the show, several changes and transformations in the narrative structures can be seen, especially in terms of the locality of each sitcom in depicting the values from the social and cultural construction where the sitcom is made. Another important thing to be taken into account is the way each society has a different construction of gender roles and sexuality, family values and so on, that lead to a different cultural product although they use and share the same conventions and characteristics of the sitcom.
\end{abstract}

Keywords: sitcom, representation, social construction, gender, family

\section{Introduction}

Entertainment programs that have been offered by the American entertainment industry seem to be a center and also trendsetter for other countries, and its influence is prominent and has become the foundation for similar entertainment programs in other parts of the world. Franchise of programs, such as American Idol (2002-present), and America's Got Talent (2006-present), for instance, after getting their syndications and airing over the years in America, began to be modified 
and become new programs with customized names in the countries that adopted the program through a private television channel, cable and satellite television. Indonesia is one of the countries that looks very interested in the concept of this entertainment program and tries to apply the success and achieve the same financial benefits in the private TV stations that America had.

The ease of the access, whether it is realized or not, slowly has given impact and also significant changes towards the production of television programs in Indonesia, as in entertainment and comedy programs for example. The variety program and comedy such as situation comedy (sitcom) and stand-up comedy performances began rapidly increasing in various television stations in Indonesia. Although the sitcom format is not originally from Indonesian culture, it does not stop Indonesian television stations from making imported sitcoms available in their daily or weekly programs for Indonesian audiences. Not only by adapting and doing a rerun or rebroadcast of the American sitcom in Indonesia, but also by producing their own sitcom as part of their scheduled shows.

Several television stations seem as if competing to start the trend of making a sitcom with local content. Some of the names are quite well-known and also last a long time, Bajaj Bajuri (Trans TV, 2004), a sitcom in which the story is dealing with Bajuri's life as a three-wheeler (bajaj) driver with his wife and in-laws in the Betawi community in Jakarta. In addition, there was also Suami-Suami Takut Istri (Trans TV, 2007), in which depicted the story of several families living in the same residential area with different ethnic and family backgrounds. The story of these two sitcoms are close with the Indonesian people's everyday life, but the format of the program is made in the form of a situation comedy which is similar with the American sitcom. Both appeared on Indonesian television for a long time and became well-known for several years, proving that this format of entertainment was favored by the local communities in Indonesia.

The trend to make a sitcom format as a main scheduled program also does not stop there, it is also still increasing to this day. One of the new television stations, NET.TV, made four sitcoms as the main entertainment program in the list of programs they have in their first years of the program. They have produced four sitcoms like Keluarga Masa Kini (2014), Tetangga Masa Gitu? (2014-present), Saya Terima Nikahnya (2015), and The East (2015). The phenomenon of the production of situation comedy in Indonesia is in fact important and needs to be observed. This is not only because the situation comedy format, which originated from America, but also because the situation comedy format is something completely different from the distinctiveness of comedy and traditional theater owned by Indonesia.

Most of the television from the Indonesian audience in the last decades was from Indonesian sitcoms. In fact, the Indonesian public has known and recognized some comedy and traditional theater as Lenong (Betawi, Jakarta), Ludruk (East Java), Makyong (Riau), Mamanda (South Kalimantan), Opak Alang (Central Java), Ketoprak (Central Java), Tarling (West Java), Ubrug (Banten), Drama Gong (Bali) 
and some forms of comedy live shows, but the format of the variety and comedy performances like situation comedy and stand-up comedy that aired on a private television channel in Indonesia gained more popularity and also the same level of as the concepts of imported variety shows that have been adopted by Indonesian television. Since the last two decades, private television in Indonesia has produced approximately more than sixty sitcoms on private television networks.

\section{Theoretical framework Narrative Conventions of the Sitcom}

Sitcom was originally introduced on the radio and only later on $\mathrm{TV}$, in the latter media it currently occupies a dominant position since its aim is to attract large audiences of a variety of age groups and interests and thus generate considerable profit. Situation comedy (sitcom) is a genre of comedy which introduces a group of characters who share a common environment (e.g. family, private life or workplace) and within a certain degree they try to solve a number of issues related to their environment as well as their everyday life. Aronson (2000) explained that "the sitcom is based around a group of people (usually about four to six regulars and two or three semi-regulars) who are either a family or operate like a family" ( $p$. 13). Beeden and Bruin (2010) also put on, "the central situation of a sitcom revolves around a group of character trapped within a continuous cycle of disrupted equilibrium, conflict, and return to the status quo" (p. 7).

There are some general features and narrative conventions of the sitcoms, but most of sitcoms follow the same characteristics. Those characteristics can be seen from the character, location/setting, timeslot/the given time for the program, the space and setting they usually use, the use of canned laughter, or also called laugh-track, to indicate or strengthen the comedy in, and also the recurring cycle of narrative structure they employ in the story.

Regarding the character, usually there are two types that one can see in the narrative structure of the sitcom. The first is the regular characters that became the center of the story and the main character in every episode. The second is a guest character, which does not always have to be present in every episode, but had a dominant function in shaping the disruption and the resolution of the situation which is preserved by the regular character. Characters in the sitcom usually have similar characteristics and have a rigid way of view about something. It was intended that the audience can see certain characters apply and react on an issue as they would normally do. As Aronson (2000) explained

The character who doesn't care much either way is an important component of sitcom. This person is the embodiment of the 'normal' point of view. Most sitcoms have a character who has a 'normal perspective' and who is surrounded by crazy people. This person serves to point out the absurdity of what is going on around him/her and is the person with whom we as an audience identify. (pp. 14 - 15).

Most of sitcoms make use of the unique and typical personalities from the characters they have. So, when the regular characters face some particular situation, 
the viewers are almost able to know how that particular character would behave to solve the problem. The particular comic idiosyncrasies of each character are sometimes known as the comic perspective of the character (Aronson, 2000, p. 14). Mendrinos (2004) also pointed out this characteristic:

Sitcoms, or situation comedies, are half-hour mini-stories featuring the same characters on a weekly basis. They are successful because the public recognizes the behavior of the characters and identifies with the situations these characters find themselves in. (p. 10)

Another characteristic that can be found in the sitcom is the setting or locations in which can be easily identified. At first, sitcom was recorded directly in front of the live audience, but slowly it was changing and now usually sitcom is recorded in the studio without any live audience (Aronson, 2000 , p. 13). The sets for the location become more limited and may only show one or two locations that do not change from episode to episode. Sitcoms usually have one or more fixed locations, which nowadays are usually settings made and located in television studios, and the audience generally can identify it. However, it is also possible to shoot at other locations, for example, in the street or a real building, depending on the theme or topic in the episode (Aronson, 2000, p. $15)$.

In terms of its structure and format, most of the sitcoms have certain timeslots given by the network. A typical sitcom has a running time of no more than half an hour. This characteristic can be seen in most of the American and British sitcoms. Even so the airtime of a sitcom may be different, depending on the platform where the sitcom was aired. Cable networks typically provide flexibility in terms of airtime, and could exceed half an hour. Neale and Krutnik (1990) also noted to this characteristic as "a short narrative-series comedy, generally between twenty-four and thirty minutes long, with regular characters and settings" (p. 233). In addition, Mendrinos (2004) also expressed more or less similar characteristics regarding the airtime of a typical sitcom. He states that:

a sitcom is a short comedic story told in jokes that is presented in a two act format and features a continuing cast of characters. Network sitcoms run approximately 22 minutes, and premium cable shows run about 25 minutes (30 minutes minus commercials). (Medrinos, 2004, pp. 229-230).

Regarding the use of laugh-tracks, at first sitcoms usually perform and do the recordings in front of a live audience, in order to get an immediate reaction from the audience from the joke, sketches and also elements of the sitcom narrative. But along with the changes and developments in the sitcom, for practical reasons, laughtrack was chosen as a replacement of the recording process in front of the audience. Even so, not all of the sitcoms are using and utilizing the laugh-track. Some classic sitcoms choose not to use the laugh-track.

Laugh-track itself is not only used to replace the immediate and original reaction of the live audience, but also to give an opportunity to the audience to feel closer to the elements represented in the sitcom narrative. Laugh-track gives the 
impression to the viewers at home that they are close to regular characters in the sitcoms they watch. The contents of the laugh-track itself can be either laughter or applause that has been previously recorded. In some sitcoms one can find the laugh-track was shown repeatedly to create a strong impression about the program. This is in line with what Aronson (2000) explained in her book, Television Writing, The Ground Rules of Series, Serials and Sitcom, she writes that "Sitcom is traditionally written for a half-hour timeslot and is shot in studios before a live audience who are primed by a comedian before the start of the show. This is changing. Many series are now shot on location without an audience. Laughter tracks may be added" (p. 13).

Another function of the laugh-track in sitcom is that viewers at home can get involved in the story, laugh of the ignorance and misunderstanding of the regular and guest characters they watch on television, and also get involved in a warm feeling when the characters find the resolution at the end of the story. Bore (2011) provided two functions about laughter track, the first is "to offer individual viewers a sense that 'we' are all watching and laughing at the program together, as a collective audience. Second, "to ensure that the comedy feels like a 'safe' space" p. 24). Sitcoms also make use of laugh-track to construct a sense of familiarity to create a link that bonds the regular characters in the program with the audiences of the show. Mendrinos (2004) added and outlined this concept:

People tend to laugh at what they know. There's a comfort in something familiar that gives us the freedom to let down our guard enough to laugh. It's also a feeling of belonging. Sitcoms use this concept all the time. In fact, they bank on it. The characters remain consistent from episode to episode and year to year. (p. 17)

This concept of familiarity is also to make the viewers/audiences of the show be able to let themselves become part of the show. So, the viewers will feel that the show that they are watching every day from their television or their network cable is close to their daily lives. Neale and Krutnik (1990) seemed to be able to summarize this, "in terms of its communalizing role, the sitcom can be regarded as a microcosm of broadcast TV in general, in that the medium attempts to inscribe the viewer as part of its own "family"' (p. 242).

\section{Narrative Structures of Sitcom}

Before the viewer gets to the given story in each episode of the program, most sitcoms customarily employ a teaser in the opening scene of their episodes. This feature has a number of functions in the narrative structure of the sitcom, first, it provides an opportunity for the audience to get a glimpse of the story that will appear in the episode, and second, to foster interest and attention of the audience to the story. This feature has become common in sitcoms, many teasers in sitcoms might not set up the plot but they usually encompass a sort of physical comedy or teasing and bantering about certain problems. The teaser itself can be related and become the continuation of the occurrence of the previous episodes, but it also can be unrelated to the story afterward. Aronson (2000) described the use of teasers as follows that sometimes, "these teasers are 
really like short comedy sketches and are often unrelated to the episode" (p. 15).

Each episode of the sitcom is in general depicting a different story or issue that becomes the center of conflict given in the program by the use of different titles for each episode. Recurrent and endless conflicts are important in the narrative structure of the sitcom. In the sitcom, the characters will encounter conflicts and disruption that can come from within or from outside their established situation. This disruption can be introduced from the beginning of the narrative or in the middle of the narrative. Neale and Krutnik (1990) described about this form of disruption and said that "the disruptions which provide the motor for the individual lots come either from conflicts within the familywhich tend to be trivialized and disavowed of serious repercussions-or from intrusions from the 'outside' which can easily be rejected" (p. 237).

The different situations that these regular characters face, frequently become the source of disruption or conflict in most of the sitcom narratives. The source of the conflict in the sitcom could come from the regular characters or guest characters. Conflicts arising from the regular characters commonly originate from error or ignorance of the regular characters. In addition, these internal conflicts can arise due to non-fulfillment of the wishes of the characters to what is desired. Another typical form of internal disruption also can be triggered from the misunderstanding or misinterpretation of the characters in dealing the situation that they have when the established situation at the beginning of each narrative is disturbed. Mintz (1985) explained that, "the problem of the situation comedy is almost always a minor threat-either an embarrassment, a confusion or misunderstanding created by a failure to communicate or an opportunity for change which equally threatens the common, familiar pattern of existence for the characters" (p. 43).

The form of disruption is also possible to be brought by the outsider or the guest character in order to create the tension for the established situation. As Aronson (2000) explained that "in sitcom, guest characters are introduced to provide a comic conflict for one or more of the regulars" (p. 17). If the presence of guest characters create a disturbing atmosphere for the regular characters, he/she is considered to be an example of external disruption. The tension that arises from the guest character can be found also in the form of intervention or influence which would require regular characters to act and do something outside of their habit or it can also be in the form of a new entity outside the normal situations that the characters have, like the disaster or occurrences that directly or indirectly have emotional impact on the regular characters.

Another form of conflict in the sitcom can be seen from the sense of entrapment incorporated in the narrative. The circumstances in which regular characters are stuck in one particular condition and do not have a free choice to do something out of the ordinary. The form of the sense of entrapment can be seen from a few examples of conditions, such as the role of children in the family, or working in an office, and others. Beeden and Bruin (2010) described these characteristics also: 
Sitcoms place the central characters within a situation from which they cannot escape, either as a domestic family or within the workplace. This sense of entrapment is vital to the continuing narrative of the series, as it ensures a return to the original equilibrium despite the conflicts that occur. (p. 7)

In sitcom, even if there might be a disruption or conflict, whether it is happening internally or externally that might be brought by their regular characters or guest characters, after a while, the sitcoms often use a complete circle and bring all the characters back to their initial condition. The disruption or the comic conflict between the regular or guest characters is normally solved at the end of the episode, this resolution to the internal and external disruptive forces are typically featured in the narrative structure of the sitcom. "Most everything is back to 'normal' at the end of the half-hour" (Mendrinos, 2004, p. 230).

The resolution of the disruption or comic conflict is in fact the way in which the sitcom narrative can continue to have its serialized characteristics and because of the resolution at the end of each episode, it makes the sitcom able to present stories and new problems in the following episodes. It is also used in order to make the episode end in a happy-ending state where the characters will be able to see their original situation in the next episode. Neale and Krutnik (1990) explained, "the sit-com relies upon a different form of repetition from the soap opera serial-the situation is not allowed to change but is rather subjected to a recurring process of destabilization-restabilization in each episode" (p. 234).
Most sitcoms do not let problems in one episode become prolonged. If the internal problems or internal disruptions come up, the resolution can be seen from the absence of further misunderstanding or confusion of regular characters and it can also be seen from the fulfillment or achievement of what regular characters wish in the beginning of the narrative. If it is due to external problems or external disruptions brought by the guest character or something outside of what regular character usually face, the typical resolution of this problem can be done in several ways, first is by expelling the guest character to be out from the established situation or by eliminating the misunderstanding between the regular character or guest character. In addition, Mintz (1985) also added that one can understand a word of 'situation' in sitcom as the main reason for sitcoms' essential characteristic, he wrote that: "The 'situation' of the sitcom is the interruption of this normality, attempts at coping with the intrusion or problem, and the resolution of it allowing for what we could call 'the return of normalcy"' (p. 42).

The Commonalities and Transformations of Narrative Structure in American and Indonesian Sitcoms

From the findings of selected episodes, the writer tried to explain the construction of narrative structure and sitcom's narrative convention in each sitcom. Even though both American and Indonesian sitcoms have some similarities in the narrative structure, there are also some differences in how certain things are developed or constructed. Some similarities and differences are viewed and compared with each other, to see what is still maintained 
and modified. Some aspects of American and Indonesian sitcoms that the writer is going to discuss are as follows: the narrative conventions in American and Indonesian sitcoms, and the narrative structure, including the teaser, and the disruption and the resolution (character developments) in the narrative of American and Indonesian sitcoms.

\section{Narrative Conventions in American and Indonesian Sitcoms}

Regarding the type of characters in American and Indonesian sitcoms, both in Friends and Indonesian sitcoms, each sitcom has two types of characters, namely a regular character and guest character. What distinguishes the two is the placement of the guest character as a source of conflict and disruption of the narrative. In Friends, guest characters often bring new problems and conflict to the regular characters in their established situation. While, in Indonesian sitcoms, the guest character's presence is not always used as a source of conflict, but what occurs in the narrative sometimes is much different, such as the presence of Jose Lorenzo on Keluarga Masa Kini in the first episode. Although Jorge Lorenzo is a guest character in Keluarga Masa Kini, his presence became one of the causes for conflict resolution in the first episode. In addition, the presence of a guest character in American sitcoms is far more dominant than in Indonesian sitcoms, because it is more frequent than in Indonesian sitcoms. Conflicts and disruptions in the narrative of Indonesian sitcoms often come from regular character, and they are more dominant than from the presence of the guest character.
Regarding the location/setting in American and Indonesian sitcoms, one can see in American sitcoms that Friends features some main setting used for the series, such as Monica and Rachel's apartment, Chandler and Joey's apartment and also a coffee house, called Central Perk, where most of the regular characters spend much of their time. In some episodes, Friends also features some outdoor scenes, but it is not always frequently presented in the series. If observed carefully, it can be seen that in Friends and two of the Indonesian sitcoms, such as Keluarga Masa Kini and Tetangga Masa Gitu, the audience can easily identify the settings of each sitcom as the location directly recorded from the television studio and not the actual location. The audience also can see that the character of the sitcom is often rarely seen outside of the main settings.

Keluarga Masa Kini and Tetangga Masa Gitu, both of these sitcoms feature some central settings, such as the living room, the dining room and the bedroom, it is very rare to see the characters going or travelling outside the boundary of their house. The sets for the location in Friends, Keluarga Masa Kini and Tetangga Masa Gitu, become more limited and mostly show one or two location that do not change from episode to episode.

On the other hand, in Saya Terima Nikahnya, this sitcom has the central setting for the series, which is the house where Prasta lives and stays together with his father and mother-in-law. What distinguishes Saya Terima Nikahnya with the previous Indonesian sitcoms (such as Keluarga Masa Kini and Tetangga Masa Gitu) are locations outside of the main settings. Saya Terima Nikahnya also 
features some frequent outdoor scenes, which allows the regular characters of the show to have some activities outside their basic situation in their home or domestic routine. In the first episode, one can see some outdoor scenes and also activities outside the house, such as Prasta's office, and apartment of his friend when Prasta has to escort her back after a celebration party in the office. In the second episode, one also can see some outdoor scenes where Prasta is repeatedly going back to the market to escort his mother and fatherin-law.

In The East, the location/setting used, is a real location. The audience can easily identify that the setting in The East, not just a set that was made in the studio. Almost the same as Saya Terima Nikahnya, the regular characters in The East are also sometimes going outside the main setting, and featuring some outdoor scenes. In Saya Terima Nikahnya and The East, the regular characters are given the opportunity to move and do something outside of the main settings, so that the probability of the potential conflict and disruption could be more diverse than if only centered on domestic setting alone.

Regarding the timeslot and the distribution of time given for each episode from American and Indonesian sitcoms, the results are as follows. Considering the overall sample selected from the sitcom of Friends, it can be seen that each episode lasted no more than half an hour. The distribution of time given in the eight episodes of Friends, it shows that they are generally circulated into two parts, one part which is then interspersed with commercial breaks and then followed up with the last part until the episode ends.
The format of each episode of Friends still makes use of the standard time of sitcom, using about half an hour per episode.

Meanwhile, observing the sample selected from the sitcom of Keluarga Masa Kini, it can be seen that each episode lasted more than half an hour, practically longer from the typical sitcom in American sitcom. The distribution of time given in the two episodes of Keluarga Masa Kini shows that they are generally distributed into more than two parts, and as a result, there is more than one part which is then interspersed with commercial breaks and then followed up with the other parts until the episode ends. At this point, the format of each episode of Keluarga Masa Kini does not really use the standard time used on most American sitcoms, which use about half an hour. Considering the content of the sitcom of Keluarga Masa Kini that also add the talk show feature in their episode, it adds more time to the program so as the result is that it becomes longer than the other sitcoms in general. On the other hand, observing the sample selected from the sitcom of Tetangga Masa Gitu, Saya Terima Nikahnya and The East, it can be seen that each episode lasted less than half an hour, using the typical standard format of sitcoms.

Regarding the basic situation in the narrative of American and Indonesian sitcoms, one can see that the basic and established situation in the narrative of Friends revolved around the lives of six people in Manhattan, New York. The characters are independent people who share a sense of family, alternative family in which the bond and their attachment to each other is derived from their friendship. While the basic and established situation in 
the narratives of Keluarga Masa Kini, Tetangga Masa Gitu and Saya Terima Nikahnya are based on the domestic routine and the interaction of each member of the family in their daily life. On the other hand, the basic and established situation in the narrative of The East is different, it revolves around the employees of Entertainment News, a gossip program in a television station. The humor and the comedy is basically derived from the interaction between the employees of Entertainment News in their workplace setting. Regarding the use of laugh-track, in the selected sitcoms in the study, they have a common characteristic in this regard. Similar with Friends, four other Indonesian sitcoms use laugh-track throughout the episode that they had.

\section{Narrative Structures in American and Indonesian Sitcoms}

From the existing findings about the teaser of narratives in American and Indonesian sitcoms, there are two types of teaser incorporated, and they are as follows: first, the teaser which is incorporated and inclined to give a short comedy sketch in the form of a conversation or funny situation before the narrative, most of the teasers in Friends episodes show this type, these teasers also have no direct relation to the narrative. Second, the teaser in which signaled the indication to narrative of the episode, this type was found in some teasers in Indonesian sitcoms, most of the teasers in Indonesian sitcoms have a relation to the story and signal the viewers about the narrative.

The forms of disruption in the sitcom could usually occur because of some reasons, 1) by internal problems, caused by the comic perspective of the regular characters, from their typical personality and behavior that each character has, or 2) due to external problems brought by the guest character or something outside of what regular characters usually face. From the existing findings about the form of disruption in American and Indonesian sitcoms, these two forms of disruption were found in American and Indonesian sitcoms, Friends episodes combined these two forms of disruption, internally and externally from the regular and guest characters in the series. Meanwhile, in Indonesian sitcoms, the form of disruption which was more commonly found was derived internally from the regular characters. The presence of guest characters in the sitcom in Indonesia is not very often the case, the conflict in the characters often arise precisely because of misunderstanding and confusion caused by their own regular characters. In addition, one of the sitcoms in Indonesia, Saya Terima Nikahnya, also used a type of entrapment in the story, so that the character in the sitcom seemed to get stuck and could not act freely because of the situation that was positioned to him.

In terms of resolution in the sitcom narrative of American and Indonesian sitcoms, there are some possible forms of resolution in the sitcom that may appear, such as 1) if the disruption or the conflict is brought by the internal problems or by the regular character's behavior and their comic perspective, those problem are typically solved at the end of episode by the act of other characters; or 2) if it is due to external problems brought by the guest character or something outside of what regular characters usually face, the typical resolution of this problem can be done in 
several ways, first is by expelling the guest character to be out from the established situation or by eliminating the misunderstanding between the regular character or guest character.

From the existing findings about the form of resolution in American and Indonesian sitcoms, these two forms of disruption were found in American and Indonesian sitcoms. Friends combined these two forms of resolution, internally and externally from the regular and guest characters in the series. Meanwhile, in Indonesian sitcoms, the form of resolution which was more commonly found in Indonesian sitcoms, was solved internally from the regular characters. The presence of guest characters on the sitcom in Indonesia has occurred, but their coming to the series is not always frequent, so if there is a comic conflict in the character between regular and guest characters, the conflict is mostly responded by clearing the misunderstanding between them, and in the end of the episode, the problem is resolved and back to normal again.

\section{Representation of Nuclear and Alternative Family}

The findings of selected episodes in Friends and Indonesian sitcoms, indicating some similarities and differences towards the trends that sitcom used in bringing the conversation and the issue of family values. In the existing findings from American and Indonesian sitcoms, Friends showed some significant changes and transformations in the issues presented in the story and the conflict at hand.

Friends still employed the family values as the primary issue, even though the family which was referred to here was slightly different from the previous discourse on nuclear family used in the sitcoms from a few decades earlier. Friends made use of the idea of alternative family, where they formed a sense of family relationship and kinship from their interaction with the friends they had outside their nuclear family's surroundings. Ross and Monica, two of the regular characters, were represented to have an actual blood relationship in Friends, while the others get their sense of family bond from their emotional and social attachment as friends in their independent lives. On the other hand, as for the Indonesian sitcoms that the writer chooses, three from four sitcoms, are actually using the model of nuclear family (which consists of the notion of husband and wife, and parent and children relationship) in their narratives.

From the existing findings from American and Indonesian sitcoms, one can also see a dissimilar treatment of parent's involvement and contribution and also the generation gap of parents-and-children relationship that each of these sitcoms has in their narrative and their regular characters' interaction. These dissimilar treatments and the parent's involvements in the observed sitcoms from American and Indonesian sitcoms could lead to the conclusion that these sitcoms also incorporate the interdependent and independent issue as part of the interaction of their regular characters.

Friends shows and reinforces the idea of being independent as a choice and also a necessity for their regular characters, while stirring their parent's involvement and their nuclear family's surroundings and influences to the degree that they are able to live independently and free as 
individuals. The problem is this decision to live independent outside their parent's control is also represented as leading them to have conflict, not only because of the generation gap between these characters against their parents' model of thinking, but also because of the misunderstanding and misconception that often lead them to have nothing in common as the glue for their relationship.

On the other hand, Keluarga Masa Kini and Saya Terima Nikahnya, both of these sitcoms show and reinforce the idea of being interdependent to each other as a necessity and an acceptable status quo. For instance, in Keluarga Masa Kini, Danang and Gista are actually old enough to live independently outside the house, but they are represented in this sitcom, in a manner where they have to keep living together with their parents. Danang in the second episode is presented as a university student that is in the process of finishing his thesis, at this point, Danang is actually old enough to go and choose to live independently outside his parent's home. Gista is also represented as someone older than Danang, and also has a job. However, they are situated in a state where they have to keep living within their parent's influences.

The similar situation also can be discovered in Saya Terima Nikahnya, Prasta has to live within his parents-inlaw's influences. Normally, newlywed couples are encouraged to live outside their parents' home and surroundings and also encouraged to live independently as a new unit of nuclear family. But, in this sitcom, Prasta is situated in an environment where he has to deal his daily basis surrounded by his parents-in-law's observation. The issue of being independent and the fair distance between the regular characters' position with their parent's involvement can be seen as not becoming the essential necessity in this sitcom.

By considering that the possibility of Keluarga Masa Kini and Saya Terima Nikahnya to follow the mainstream discourse outside their narrative, it can be implied that the established situation represented in these sitcoms are actually common in Indonesian culture and society, where the children live together in the same house with their parents until they decide to go or move out after being married and starting their own family. Also, the established situation that the sitcom of Saya Terima Nikahnya also represented is actually a common practice for a newlywed couple. However, it is also important to consider that the practice of this independent and interdependent issue in these sitcoms might not always be identical to the reality outside the narrative.

Following the earlier discussion about the independent attitude that is represented in Friends. In Friends, it can be seen that the family values are reinforced and displayed on their daily interaction from each character. Moreover, one can see and also notice that their involvement and contribution to each other's life, is not based on biological ties, but from the friendship and the social attachment they have from each other. The presence of parents (Ross and Monica's parents) on the sitcom Friends is found, but it does not have great significance towards the narrative in the series. They only appear in a small number of episodes and they are 
often situated as the external source of the established situation.

The representation of the regular characters' decision to have independent life is what actually gives the distance between each character with the involvement of the parents over many decisions that they have. This gives an idea of the interfering portion of the nuclear family of each character in Friends. Parental involvement is limited, because they have grown and started to live alone, and begin to be responsible with the works and the choices they make. While, in Indonesian sitcoms, parental involvement is present and also important to be acknowledged, because the cultural and social construction of family in Indonesia relies on towards the interdependence of members of family to help each other as a part of accepted social norms in the community.

The interdependence of a member of family to each other's company is already becoming a common thing in Indonesia, as for Indonesian people, the decision to stay close and keep in touch with family is something that would be really appreciated and encouraged. It becomes normal and common knowledge that sometimes even the nuclear family influence is still felt significantly in the lives of those who are already married. For Indonesian people, the intense communication and regular meeting is how each member of the family gets the opportunity to be able to help each other and find out the latest news from the family. Lamoureux (2003) noted about this characteristic in Indonesian culture, that:

The family is the primary unit in Indonesia. From infancy through old age an Indonesian remains close to his or her parents and siblings. Prior to independence, generations of families tended to stay in the same village. In the twentieth century, as more people became educated and opportunities were limited in the villages, many villagers relocated to urban areas. However, even family members who have moved away return to their villages to visit as often as they can, and always for the Idul Fitri holiday at the end of the fasting period of Ramadan. (p. 129)

Parental involvement and a sense of interdependence give a significant impact on how family relationships are run in Indonesia. It is an obligation to be good and dutiful to parents and it is also a social act that must be kept by family members until old age. A sense of dependence on each other also represents the spirit of the people of Indonesia, especially when confronted with a problem, the desire to unite to address the problems becomes the basis of social relations in Indonesia. Mutual cooperation is a necessity and also the identity of the people of Indonesia.

\section{Representation of Gender Roles}

From the findings in the selected episodes of Friends and Indonesian sitcoms, it could be seen that Friends demonstrated many different interpretations about gender roles which the series tries to represent in its storylines. While, in Indonesian sitcoms, the findings from selected episodes indicated only a few gender roles given to the character, especially for their women's roles in the family.

In Friends, the characters are given some roles in which they are represented in many different public domains, they 
participated in some activities outside domestic domain. This representation is possible through the regular characters' representation in the workplace and outside their domestic routine, in which they participate and also contribute to getting their personal income and independence, and are not portrayed as a 'homemaker' as similar to the previous representation for most of women in classic sitcoms.

There have been many changes in the perception and the acceptance of women to be involved and have a presence in the workplace setting and also the emergence of dual-earner families in American society which has gradually changed the model of traditional nuclear family which incorporated the idea of a man/a husband as a breadwinner and woman/a wife as a homemaker, and has provided equal opportunity for women to be outside the domestic setting (Hertz and Marshall, 2001, p. 1). This could be one of the reasons why the representation of women in Friends can be very broad and flexible. Of Rachel, Phoebe and Monica, each has a job and earns their own income. They have control and power, which does not limit them to sit at home and wait for the men to bring economic support.

A significant boost after the human rights and womens movement in the 1960s has accompanied the changes in the family structure in America. The involvement of women in various fields became wider and more diverse. It is also in line as it was described by Waite and Nielsen (2001), in regards to the rise of dual-earner families in American society:
Between 1963 and 1997 we see the rise of the dual-worker family. By 1970 the breadwinner/homemaker family was no longer a majority even among married couples, and more than one couple in four had two full-time earners. The transformation accelerated during the following decades, so that by the mid-1980s families with two full-time earners predominated. By 1990 out of every ten married couples, more than four had two full-time earners, more than two had one full-time and one parttime earner, and fewer than three followed the traditional breadwinner/homemaker model. (p. 30)

While, in Indonesian sitcoms, most of the representation of women in terms of their roles in the family is fixated on two roles, being a mother and a housewife, and only some of the regulars are represented as career women. It is evident in three Indonesian sitcoms, such as in Keluarga Masa Kini, Tetangga Masa Gitu and Saya Terima Nikahnya, there is only one sitcom that represented a new trend in the representation of women outside their domestic routine in Indonesian sitcoms, namely The East.

In Indonesian sitcoms, one can see that most of women characters are situated within the domestic routine, in which their roles are fixated in being a mother (if represented with a child) and being a housewife. It is also visibly seen in Keluarga Masa Kini, Sarah and Hesti are situated in their domestic routine, being the 'homemaker', while their husbands, Farhan and Febri, are situated as a 'breadwinner', who will provide their wives money and participate in realizing their roles as husbands. In Tetangga Masa 
Gitu, Bintang is also portrayed as a housewife, taking care of the house while her husband, Bastian, is working outside. Although, in some episodes, Bintang is given a chance to go and work outside the house, this chance of Bintang to maintain her position to work outside is always temporary, because in the next episode or in the end episode, she will go back to being in the house and follow her basic role as a wife. However, Angel is situated in a different representation, Angel is represented as a career woman who worked at the law firm.

The same also goes for Saya Terima Nikahnya, Kirana and her mother, are also represented as housewives, who happen to maintain and clean the house and shop for family purposes in daily routines. While Kirana's husband, Prasta, goes to the workplace and becomes the head of the family, as similar to Prasta's father-in-law. Their role is as husbands who provide the needs of their family. A slightly different representation can be seen in the last Indonesian sitcom that the writer selected, The East, where men and women work together in the same program. In this sitcom, women have positions and also rank high in the work phase. Women in this sitcom are situated in many important positions, for example, the representation of Dian as the Director of the program of Entertainment News. Women in this sitcom are not placed on domestic routines, they are represented in situations that allow them to par with men in terms of ability and also the chance to be higher than men in the achievement and quality of work.

By considering the influence of Suharto and the New Order that lasted quite a long time in Indonesia, the construction of gender and sexuality were strongly invested by the State ideology. The construction of gender and sexuality can be seen from the repetitive images and ideas about the roles and duties of women in society. The role of women in their duties as a mother in the family is considered to be important, in their duty to provide protection to children and become the shelter for their families. The idea of women as mothers has survived so long because it is also supported by scholars of Islam who are also part of the majority in Indonesia and incorporated the notion that the role of women as mothers is indeed also based on religious orders,

Since the inception of Suharto's New Order in 1965, the Indonesian state has avidly pursued a policy promoting nuclear families and motherhood. Although the Indonesian state claims to have emancipated women, giving them greater access to education and some occupations, during Suharto's rule from 1966-1998, the state enshrined mother and wife as women's primary role and duty. (Blackwood, 2007, p. 295)

Moreover, in the context of Javanese culture, the emphasis of the role of women as mothers and housewives also has an important role, because being a mother means maintaining family honor and also maintaining the prestige of the husband in the community (Niehof, 1998, p. 245). The role of women in public domain in previous decades existed, but was limited to a few situations, such as participation of women in the Dharma Wanita or PKK activities when their husbands were civil servants (Niehof, 1998, p. 251). The influence of the New Order regime in 
Indonesia has created strong ideas about women, which reinforce the construction of gender and sexuality over their role in society.

The role of Islamic scholars and also the state ideology, especially under the leadership of the New Order, were influential in contributing to the identity formation of women in Indonesia (Blackwood, 2007, pp. 294-295). Changes in the discourse and viewpoints regarding the role of women is changing gradually, especially since the reform era in Indonesia. Since the reform era, the trend over the role of women as mothers or women as housewives slowly started to change due to access for women to education and new discourses about gender equality. In the last decade, the trend of women to be more career women and work outside the home is more abundant and also has become an option for women in Indonesia. The idea of the role of women as mothers is still there, but is not fully enforced and emphasized as an obligation. Women's participation in public domains is increasing and women can be seen in various fields of work.

\section{Representation of Sexuality}

Based on the findings in the selected episodes of Friends and Indonesian sitcoms, it is clear that Friends demonstrated many scenes in which the series tries to represent an open discussion about sexual conversations and activities. Friends presented the viewers with a number of characters who engaged in sexual relationships and also openly discussed about sexual orientation and also gay parenting. Indonesian sitcoms are seen to carefully pick out these references to sexual activities in a different way. Indonesian sitcoms do not really expose the issue of sexuality within their narrative in an open way; the viewers may see a scene where the regular characters spend time in their bedroom, having a conversation or doing something, but their representation is limited to that and it does not really explore any other sexual dialogue or activity.

This openness of American sitcom, especially in Friends, in its reference to or depiction of sexual activities almost can be seen in every episode in the selected episode of Friends. For instance, in the restaurant when Monica and Paul the Wine have their date in the first episode in season one, Paul says that he is going to tell Monica about his 'fifth date kinda revelation' in which he revealed that he has not been able to perform sexually for almost two years. This conversation seems to be accepted and does not bother Monica. Monica is surprised to know that Paul has not done any sexual activity for such a long time. Moreover, Monica jokes about that by saying: "I know being spit on is probably not what you need right now." In the scene of the next morning, the viewers can see that Monica engaged in sexual activity with Paul after they went home from the restaurant. In the morning when Paul is leaving Monica's apartment, Rachel says that she sees Monica look so happy because she smiles all the time, Rachel tells a joke about Monica's situation and says: "You look like you slept with a hanger in your mouth."

In the selected episodes of Friends that the writer chose, one may see more about this depiction of sexual encounters or sexual conversations from the regular characters. 
Another example can be seen in the opening scene of the fourth episode, when Ross and Monica see Phoebe sleep on the couch in the Central Perk. Not long after that, Phoebe wakes up and tells them that she did not get enough sleep because of her grandmother's boyfriend visit the previous night. One can see that Phoebe actually shared the sexual activity of her grandmother with her new boyfriend. It is unlikely to happen or be clearly represented in Indonesian sitcoms. These kinds of stories most likely are kept hidden as secrets and the thought of sharing it in public spaces and to someone else is also sometimes considered as rude or impolite. However, Phoebe does it casually as if it was not a secret or a taboo conversation to be shared with her friends. There is also another conversation in reference to sexual activities that the regular characters have in the fourth episode of the series. This time it is Ross who shares his reasons why the day when he and Chandler and Joey also went to hockey game became memorable for him. Ross says that it was the first time that he did a sexual activity with a woman, and that woman was Carol.

In Indonesian sitcoms, the kind of openness for sexual conversation or reference to sexual activities is indirect and presented in a more subtle way. In Keluarga Masa Kini, one may find some of the moments when Sarah and Farhan sleep or talk in their bedroom, but the openness that Friends exhibited in its sexual conversation or sexual activity is not visibly represented in Keluarga Masa Kini. The close one may only be seen in the first episode of Keluarga Masa Kini when Sarah is waking up in the night because of the disturbing noise of illegal racing outside their house and also from the closing scene in its first episode, when in the night, Farhan wears a racing suit to surprise and lead on Sarah's excitement, as he is going to sleep with Sarah. The second episode of Keluarga Masa Kini also does not clearly present any sexual conversation or activity to the point of their narrative. The same thing also applies to Tetangga Masa Gitu and Saya Terima Nikahnya, one may also get the idea of regular characters spending time in their bedroom, but there is nothing like visible sexual activities shown in those sitcoms.

Regarding the cultural and social context beyond the narrative in American and Indonesian sitcoms. In the Indonesian culture, to express and refer to the sexual organs in front of others is considered dishonorable. Even though the conversation was shared between friends, if it was expressed. Often there was euphemism in the choice of words used to avoid direct reference to the genital or certain sexual activities (Forshee, 2006, p. 154). Moreover, talking about sexual experiences, is strange and unnatural behavior for Indonesians. The embodiment of the shame feeling in these kind of conversations serves as the way people of Indonesia maintain a polite social behavior toward the other person and also to the personal identity of the speaker. Forshee (2006) identified this characteristic in Indonesian culture:

Yet, when spoken of or displayed in a vulgar manner, private parts of the body symbolize the socially shameful-reflecting lowly character on the part of the offender. This dualism carries through much of Indonesian culture, while reinforcing ideal social behavior. (p. 154) 


\section{Representation of Premarital Sex}

Throughout the selected episodes of Friends, Friends displayed some casual sex occurrences, when a regular character of Friends engaged in sexual activities with their partner (boyfriend/girlfriend) although they are not officially married or serious about the issue of commitment before that. While in Indonesian sitcoms, one can see that there is no such thing as casual sex or sexual relationship, which is not legal by law represented in those episodes.

Regarding the cultural and social context beyond the narrative in American and Indonesian sitcoms. One can see that initially, especially in the nineteenth century, the institution of marriage was still dominant. Most of American people still lived in the middle of a farming family, which quite focused on providing the support of one another. Marriage was still considered as something important and necessary, the divorce or decision to be a single parent never once existed. However, along with economic change and the impact of massive industrialization in America, some things began to change and influence the perception of marriage in America (Amato, 2007, p. 12).

In American society, the trends of being in a marriage institution have been drastically changed over time. There are some changes in American public attitude towards the relationship in terms of marriage and before marriage. In the United States a new trend is beginning to emerge in which a person chooses to live together before marriage. If indeed there is a desire to continue to marriage. It is usually after a long relationship between two people. This phenomenon appears along with the trend of divorce and failed marriages in the United States which have occurred in the last half century. American public perception is slowly changing. In the past, married people would stay together until the spouse died. Nowadays it is no longer the case. Along with the individualism that encourages Americans to pursue personal happiness, slowly the idea of marriage become a choice and is no longer an obligation in American society (Amato, 2007, p. 1-2).

In Indonesian culture, the institution of marriage is still considered important and also dominant. In Indonesian society, there is one thing that is important and mandatory for men and women, such as to maintain the sanctity until the time of marriage. This indirectly implies that any form of relationship outside of the institution of marriage does not get a place in the culture and society of Indonesia. Living together in any form is not acceptable, it is in order to avoid premarital sex and an unwanted child. In addition, concern about the sanctity of a man and a woman is the responsibility of parents and the family, who cannot be ignored (Bennet, 2005, p. 19). Sanctity of girls in the family affects the social status and honor of an Indonesian family in public,

Indonesian Muslims typically support the ideal of premarital chastity for both women and men, although the value attributed to female virginity is generally greater. The regulation of female sexuality prior to marriage is also sustained by a number of other key ideologies such as state development policy and local custom (adat). (Bennet, 2005, p. 9) 
If the woman is known to be no longer a virgin, social sanction in Indonesian society and culture is still very strong. Sanctions can be in the form of social exclusion and verbal abuse against the offender and family, then they are also not given space to move freely in society afterward,

The personal and familial shame associated with premarital pregnancy for some women is so great that they choose to run away from home in order to avoid shaming their families. Others are sent to live with relatives in distant regions of the country until a child is born or a spouse acquired. (Bennet, 2005, p. 19)

\section{Conclusion}

The repeated use of the issue of family and domestic routine has led sitcoms to be identical with family values. The representation of the interaction of the nuclear family such as father, mother and child, or husband and wife in a few decades in the development of American sitcoms showed a trend in which the value of the family is important. No matter how different all the family members view are all can be resolved in the midst of warm interactions and relationships within the family.

Some changes and transitions in the social sphere, political discourse and cultural manifestation give much influence to the representation shown in the sitcom, and it is evident in American and Indonesian sitcoms. However, the possibility of a different representation of the social and cultural situation in the community on a sitcom is very likely to occur. However, as it was also mentioned in the earlier chapters, the sitcom is often believed to follow the mainstream discourse in society and often tries to mirror it through representation in the narrative. Thus, taking that into account at some point, the sitcom could be regarded as reflecting the popular discourse in the society.

The findings of selected episodes of Friends and Indonesian sitcoms, indicating some similarities and differences towards the trends that sitcoms have used show that it is likely that American and Indonesian sitcoms use almost the same conventions of the sitcom narrative. Nonetheless, they also show some differences in the content of the show and several changes and transformations in the narrative structures can be seen, especially in terms of the locality of each sitcom in depicting the values from the social and cultural construction where the sitcom is made. For instance, one can see that Friends showed some significant changes and transformations in the issues presented in the story and the conflict at hand.

Friends still makes use of family values as the primary issue, even though the family which is referred to is slightly different from the previous discourse on nuclear family used on the sitcom in a few decades earlier. Friends makes use the idea of alternative family, where they form a sense of family relationship and kinship from their interaction with the friends they have outside their nuclear family's surroundings. Ross and Monica, two of the regular characters were represented as having the actual blood relationship in Friends, while the others get their sense of family bond from their emotional and 
social attachment as friends in their independent lives.

On the other hand, as for the Indonesian sitcoms that the writer chose three out of the four sitcoms, use the model of nuclear family (which consists of the idea of a husband and wife, or parent and children relationship) in their narrative, these sitcoms are Keluarga Masa Kini, Tetangga Masa Gitu and Saya Terima Nikahnya. While the last sitcom, The East is a workplace sitcom, and the narratives revolve around the interaction between the employees in the production of the entertainment news, it is not in a domestic routine or about family.

The similar observation can be applied too to the construction of gender roles and also sexuality in these sitcoms. The cultural and social background from each sitcom is seen to influence and contribute to the way certain things get their representation in the narrative, and the American sitcom reinforces and promotes some accepted values and trends in their society from the regular characters of the sitcom. The fact that in America sitcoms also play a significant role in the television network, the popular and successful sitcoms can be considered to document the changed perception about a lot of on-going important issues in the society. The openness for many discourses in the narrative of American sitcoms can be concluded as a way to see the way America gives chances to many interpretations for some issues and make them possible without a rigid representation. However, the same thing does not really fit in the Indonesian society at this moment, because as also reflected in the narrative in Indonesian sitcoms, certain issues are not well-discussed in the narrative. The influence of the New Order and state ideology in the earlier decades in Indonesia were manifested so deep in the society, and these influences were also supported by Islamic scholars for certain images and representations in the media. Some issues are sometimes left behind and forgotten.

Another important thing to be taken into account is the way each society has a different construction of gender roles and sexuality, family values and so on, that leads to a different cultural product although they use and share the same conventions and characteristics of the sitcom. At this point, one can see that the locality and the formation of national identity in each sitcom is established, even though the platform is similar, but the way it is represented to their national audiences is different.

\section{References}

Amato, P. R. (2007). Alone Together. United States of America: President and Fellows of Harvard College.

Aronson, L. (2000). Television Writing, The Ground Rules of Series, Serials and Sitcom. Australia: Australian Film Television and Radio School.

Beeden, A and Bruin, J. (2010). The Office: Articulations of National Identity in Television Format Adaptation. Television \& New Media, Volume 11 Number 1, January 2010, pp. 3-19.

Blackwood, E. (2005). Sexuality in Indonesian Discourse: Normative Gender, Criminal Law and Shifting Strategies of Control. Culture, Health \& Sexuality, Vol. 9, No. 3, 
Selected Papers from the IASSCS Conference 2005 (San Francisco) (May - Jun., 2007), pp. 293-307.

Bore, I. K. (2011). Lauging Together: TV Comedy Audiences and the Laugh Track. The Velvet Light Trap, Number 68, Fall 2011, pp. 24-34.

Bennett, L. R. (2005). Women, Islam and Modernity. London: Routledge.

Forshee, J. (2006). Culture and Customs of Indonesia. Westport, Connecticut: Greenwood Press.

Hertz, R. and Marshall, N. L. (2001). Working Families. Berkeley: University of California Press.

Lamoureux, F. (2003). Indonesia. Santa Babara, Caliornia: ABC-CLIO.

Mendrinos, J. (2004). The Complete Idiot's Guide to Comedy Writing. United States of America: Alpha, Penguin Group Inc.
Mintz, L. E. (1985). Ideology in the Television Situation Comedy. Studies in Popular Culture, Vol. 8, No. 2 (1985), pp. 42-51.

Niehof, A. (1998). The Changing Lives of Indonesian Women: Contained Emancipation under Pressure. Bijdragen tot de Taal-, Land- en Volkenkunde,Vol. 154, No. 2, Globalization, Localization and Indonesia (1998), pp. 236-258.

Neale, S. and Krutnik, F. (1990). Popular Film and Television Comedy. London, United States of America and Canada: Routledge.

Waite, L. J. and Nielsen, M. (2001). The Rise of the Dual-Earner Family, 1963-1997. In R. Hertz and N. L. Marshall (2001). Working Families. Berkeley: University of California Press. 